\title{
THE DIFFERENTIATION OF THE DECIDUA AT OVO-IMPLANTATION IN THE GUINEA-PIG CONTRASTED WITH THAT OF THE TRAUMATIC DECIDUOMA
}

\author{
R. DEANESLY \\ A.R.C. Institute of Animal Physiology, Babraham, Cambridge \\ (Received 30th October 1970)
}

\begin{abstract}
Summary. The rapid decidualization of the endometrial stroma, which begins while the guinea-pig blastocyst is still passing through the uterine epithelium, has been compared in serial sections with the decidualization following thread traumatization in the same or similar uteri. In both cases there are localized alkaline phosphatase reactions, but blastocyst implantation leads to formation of a decidua which within the first $24 \mathrm{hr}$, is more organized and differentiated than the corresponding traumatic deciduoma. The passage of the guinea-pig blastocyst through the uterine epithelium does not involve cell destruction or phagocytosis and the decidual changes in the stroma must be attributed to specific blastocyst activity.
\end{abstract}

\section{INTRODUCTION}

Earlier work (Deanesly, 1967) showed that the pregnancy decidua developed very rapidly in the guinea-pig at a time when non-pregnant uteri in the same females, traumatized 3 or 4 days after mating, remained apparently unreactive. The present study has been extended to earlier implantation stages before and after the blastocyst passes through the uterine epithelium. Material has been processed to show the presence of glycogen and lipids and the alkaline phosphatase reaction.

Finn \& Hinchliffe (1964) described alkaline phosphatase found in association with implantation sites and oil-induced deciduomata in mice and Manning, Meli \& Steinetz (1966) have assayed alkaline phosphatase in pregnant and sterile uterine horns in rats. They found enhanced phosphatase activity localized exclusively at the implantation sites and they attributed this to an interaction between the implanting blastocyst and the hormonally conditioned uterus. It is thought that the presence of alkaline phosphatase is associated with active cell differentiation such as occurs during decidualization.

\section{MATERIAL AND METHODS}

For animals and operations, methods were the same as in earlier work 
(Deanesly, 1967). The morning of the appearance of a vaginal plug was recorded as Day 0. Blastocyst implantation was studied in a normal series and also in females in which one uterine horn, previously rendered sterile, was traumatized by thread, Arbrasilk no. 2. This was left in position till fixation was complete.

The uterine horns were fixed in Bouin's fluid for staining with haemalum and eosin or PAS staining for glycogen. Other fixatives were $10 \%$ formol saline or Ciaccio's fluid for lipids; for alkaline phosphatase, Gomori's method, as given by Culling (1963), was used. Most uteri were cut in serial sagittal sections at $7 \mu \mathrm{m}$; in some cases transverse sections were also cut. Cell division during early decidualization was studied in some animals injected with Colchimid (Ciba), $1 \mathrm{mg} / \mathrm{kg}$ body $\mathrm{wt}, \mathrm{l} \frac{1}{2} \mathrm{hr}$ before death.

With Gomori's method, areas with alkaline phosphatase activity blacken and nuclei are stained red. In the guinea-pig uterus, the secretions of the endometrial glands, which are not involved at ovo-implantation, blacken, but there is no blackening of the epithelium of the glands or of that of the uterine lumen. In pregnant and non-pregnant uteri, a faint diffuse reaction for alkaline phosphatase may occur in some stroma cells, but this is quite distinct from the conspicuous localized blackening in the early stages of the implantation decidua or traumatic deciduoma. Contrary to the statement of Aldeen \& Finn (1970), it does not extend along the length of the uterus.

\section{OBSERVATIONS}

\section{Unimplanted blastocysts 4 and 5 days after mating}

At 4 days after mating, free blastocysts were present in the uterine lumen of three guinea-pigs. In formol-saline-fixed material, an intact zona pellucida could be seen; there was no localized stromal reaction distinguishable in serial sagittal sections though many stromal cells were in mitosis, and, particularly in one uterus, blood vessels were prominent. No localized alkaline phosphatase reaction could be distinguished in the vicinity of unimplanted blastocysts.

In one female, one of three blastocysts lay near a shallow depression in the uterine epithelium (P1. 1, Fig. 1) in which the cells were lower than in the adjacent epithelial areas; another blastocyst was actually touching the epithelium and in process of losing its zona. Blastocysts at this stage, also found at Day 5 , were near attachment (Stage 1), but had not yet stimulated a differentiated decidua, although the uterine stroma was proliferating and vascular.

At 5 days after mating, six guinea-pigs contained unimplanted blastocysts, most of them lying near, and in one case touching, shallow depressions in the luminal epithelium. The stroma was very vascular throughout the uterus and many mitotic figures could be seen both in colchicine-treated and normal animals. Only in one uterus did there appear to be a definite localized early stage decidua behind a typical shallow depression in the uterine epithelium, from which the actual blastocyst had been lost in processing. From a comparison with the rest of the series, it would seem that here penetration by the blastocyst had just begun, but this could not be determined with certainty. At 5 days, most of the unimplanted blastocysts were actually in contact with the 
slightly modified, but still intact, epithelium, although fixation tended to detach them from it. The zona, present in earlier free blastocysts, was now being shed. In formol-saline-fixed sections, fusion of the two surfaces of the uterine epithelium could be seen at about this time in some areas.

Since guinea-pigs ovariectomized 3 days after mating implant normally (Deanesly, 1960), the loss of the zona just before penetration of the epithelium seems to be independent of any contemporaneous secretion of ovarian hormones.

\section{Early implantation stages 6 days after mating}

In six guinea-pigs, five killed between 06.30 hours and 14.30 hours and another killed at midnight on Day 5, embryos were in process of passing through the uterine epithelium (Stage 2). A gap in the epithelium was still present though sometimes appearing only in one section. The blastocysts resemble those described and illustrated by Sansom \& Hill (1931) (Pl. 3, Fig. 14). The trophoblast is spreading out in contact with the subepithelial tissue. In the present series, the blastocyst appears to induce a gap in the uterine epithelium without destroying any cells. From the number of blastocysts seen part way through the epithelium, it can be inferred that the process is slow. Decidual formation becomes apparent on either side of the lumen as soon as contact is made with the subepithelial stroma (Pl. 1, Fig. 2, Pl. 2, Figs. 5, 6, 9, and Pl. 3, Fig. 12). Localized decidual development can readily be distinguished in sagittal sections through the uterus at this stage. The decidual cells showed alkaline phosphatase activity unlike those of the undifferentiated stroma. In colchicine-treated material, mitotic figures were common in the stroma surrounding the decidual area but not in the decidua itself. The decidual cells with round vesicular nuclei of varying diameter formed a denser mass than the adjacent stroma from which they derived (Pl. 1, Fig. 1, and Pl. 2, Fig. 7). In material fixed by Ciaccio's method and stained with Oil Red O, some lipid could be seen in decidual cells, but it was not abundant.

It is remarkable how rapidly decidualization and differentiation are induced by the penetration of the blastocyst. In some serial sagittal sections, the decidual area extended to $630 \mu \mathrm{m}$, and in others at about the same stage it extended for 504 and $560 \mu \mathrm{m}$.

\section{Later 6 day stages}

In the six animals of this group, the blastocysts had passed through the uterine epithelium and were enclosed in the now differentiated decidual tissue (Stage 3; Pl. 3, Figs. 12, 13, 14). Adjacent to and distinct from the trophoblast with its fine reticulum, can be seen the maternal symplasma, which has small dark nuclei compared with the larger vesicular nuclei of the surrounding decidual tissue. Alkaline phosphatase preparations of three implantation sites at this stage and later show marked blackening of the large decidual cells, while the maternal symplasma in general does not blacken. In PAS-stained preparations, cells with glycogen granules are conspicuous at the outer edges of the decidua (Pl. 3, Fig. 14). Lipid-containing cells occasionally occur among the decidual cells but they are not abundant.

Mitotic figures are again common among the stroma cells round the edges of 
the decidua, but not in the decidua itself. The decidua has greatly enlarged in the last 12 to $24 \mathrm{hr}$ and may extend through more than 100 sections. At the level of the embryo, the decidua may measure $620 \times 675 \mu \mathrm{m}$.

\section{7 and 8 day stages}

At 7 days, the blastocyst has increased in size and the cylindrical mass including the ectoplacental trophoblast projects into the blastocyst cavity. This is somewhat enlarged in Pl. 1, Fig. 3 owing to fixation shrinkage. The blastocyst

\section{EXPLANATION OF PLATES 1 TO 3}

Sagittal sections through uteri 5 to 8 days post coitum (p.c.).

PLATE 1

Sections stained to show alkaline phosphatase

Fig. 1. No. 59; 5 days p.c. Blastocyst near implantation. Note the thinned epithelium of the lumen from which the blastocyst has probably been detached during fixation. $\times 130$. FrG. 2. No. $65 ; 6$ days p.c. Blastocyst penetrating the uterine epithelium. The alkaline phosphatase reaction, thickest on the mesometrial side of the lumen, is only slight in this preparation in the immediate vicinity of the blastocyst which is shown at a higher magnification in Fig. 9. $\times 130$.

Frg. 3. No. $77 ; 7$ days p.c. The decidua round the implanted blastocyst has already differentiated into an outer area with the alkaline phosphatase reaction and an inner small cell area, the maternal symplasma, which does not show this reaction. The alkaline phosphatase is more abundant on the mesometrial side of the embryo, which lies in the decidual cavity. $\times 53$.

Frg. 4. No. $68 ; 8$ days p.c. The embryo has become tube-shaped with the amnio-embryonal mass lying at the closed end. The differentiated decidua by now has extended over a much wider area than in No. 77, and again alkaline phosphatase is more abundant on the mesometrial side of the embryo. $\times 53$.

\section{PLATE 2}

Early implantation stages; 6 days p.c.

Figs. 5 and 6 . No. 62. Sagittal sections through two adjacent implantation sites in the same uterus; deciduas are already distinguishable although the blastocysts have not yet passed through the epithelium. $\times 33$.

FIGs. 7 and 8. No. 109. Adjacent sections showing a blastocyst part way through the epithelium and trophoblast with dark staining nuclei. No cell degeneration can be seen. $\times 520$.

FIg. 9. No. 65. The blastocyst from Pl. 1, Fig. 2, later than that of Figs. 7 and 8, showing the covering trophoblast, the blastocyst cavity and the further penetration of the stroma by the parietal trophoblast with its clumped nuclei and foamy cytoplasm. $\times 520$.

Fic. 10. No. 65. An early implantation stage from the same section as Fig. 9. Here, unusually, the luminal epithelium appears to be growing up round the blastocysts, perhaps as the circumvallation seen and described by older embryologists, cited by Sansom \& Hill $(1931) . \times 520$.

\section{PLATE 3}

Development of decidua and deciduoma: 6 days p.c.

Fig. 11. No. 78. Section through implantation site, missing the actual embryo which is still traversing the uterine epithelium; already the decidua is spreading out beyond the invading trophoblast. Capillaries are darkly stained in this PAS section, and some decidual cells, bottom right, show glycogen granules. $\times 350$.

FIG. 12. No. 109. Vascular decidual area round an implanting blastocyst (P1. 2, Figs. $7,8) . \times 130$.

Fig. 13. No. 83. Blastocyst with parietal trophoblast lying in decidual cavity (Stage 3). $\times 130$.

Fig. 14. No. 127. A later 6-day embryo with differentiated decidua. PAS-stained glycogen granules are present at the outer edges. The lymphocytes near the embryo have apparently migrated from the traumatized area nearby. $\times 110$.

Fig. 15. No. 127. Early deciduoma, 1 day after Day 5 traumatization, adjacent to the implantation site in Fig. 13. Nuclear enlargement and cell division have been stimulated, but the stromal tissue is not organized and differentiated as it is round the embryo. $\times 110$. 
PL $\triangle$ TE 1

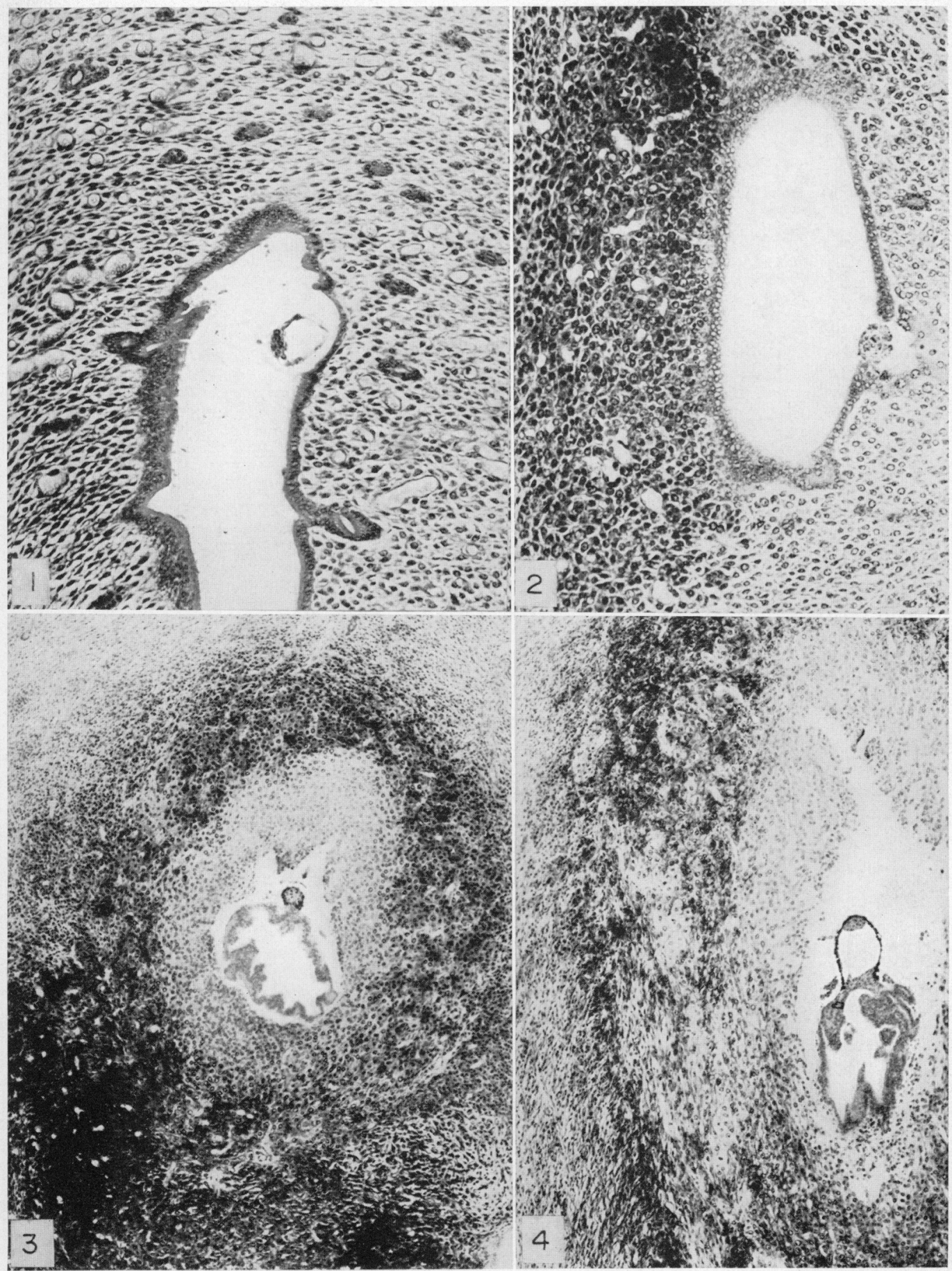

(Facing p. 94) 
PLATE 2
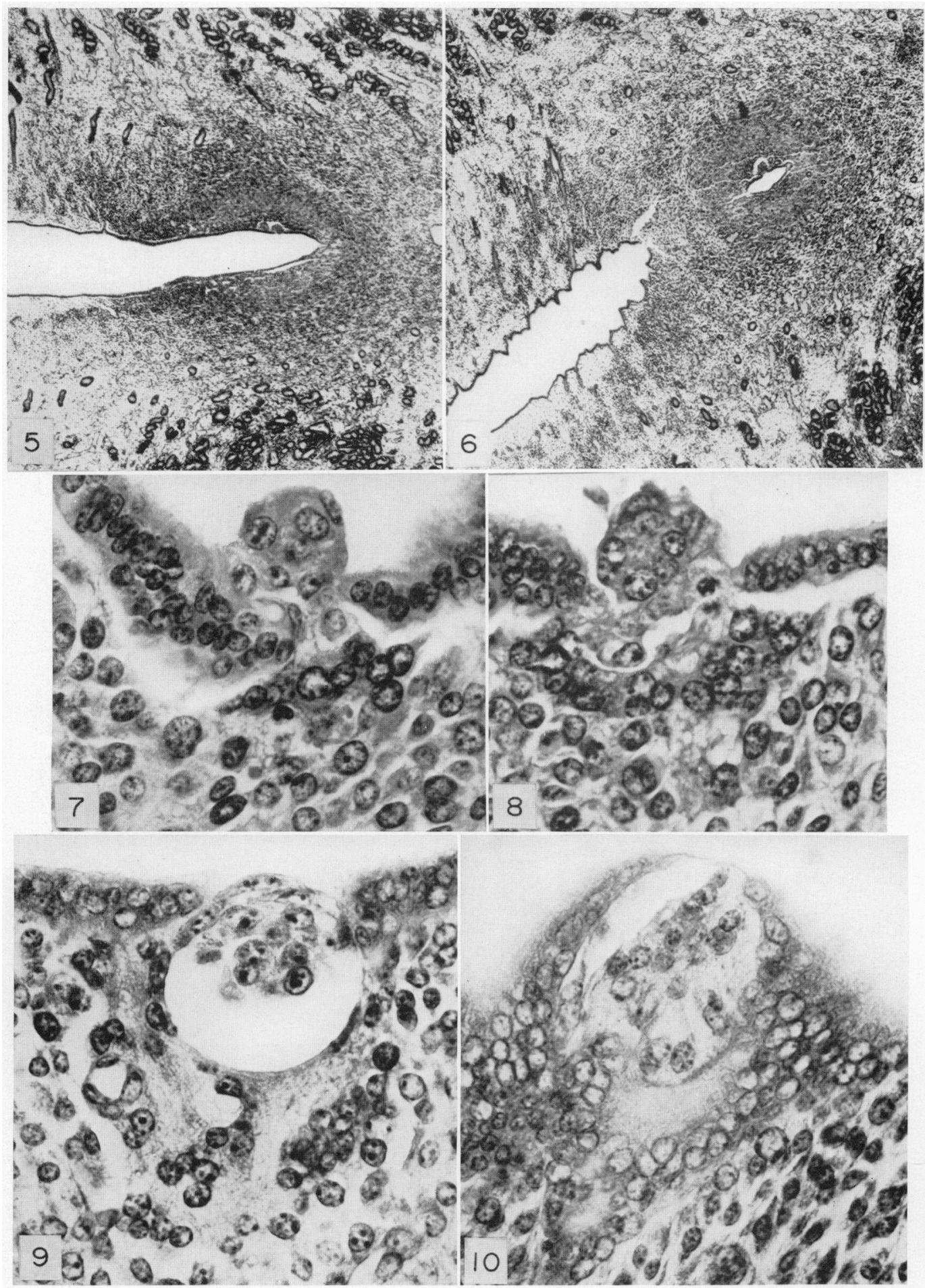

60 to

cos 6 .

0.

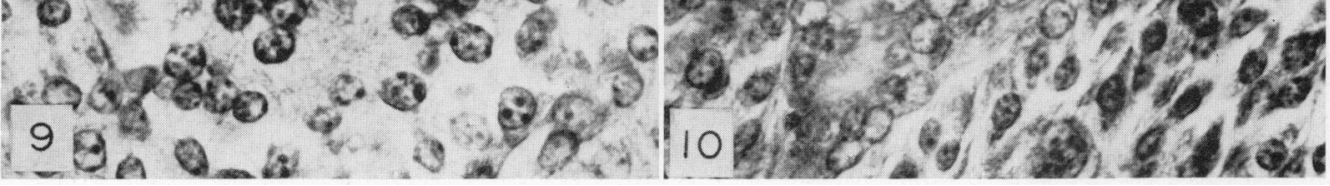

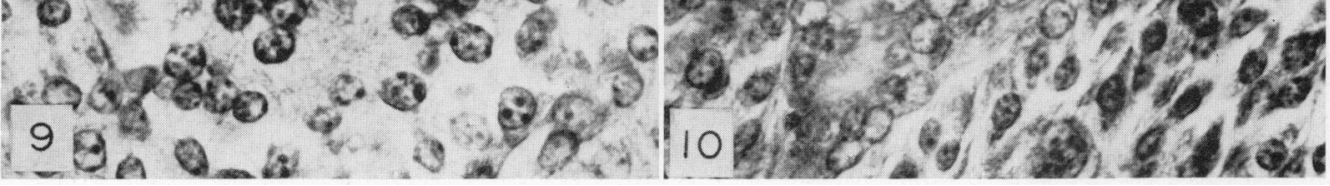


PLATE 3

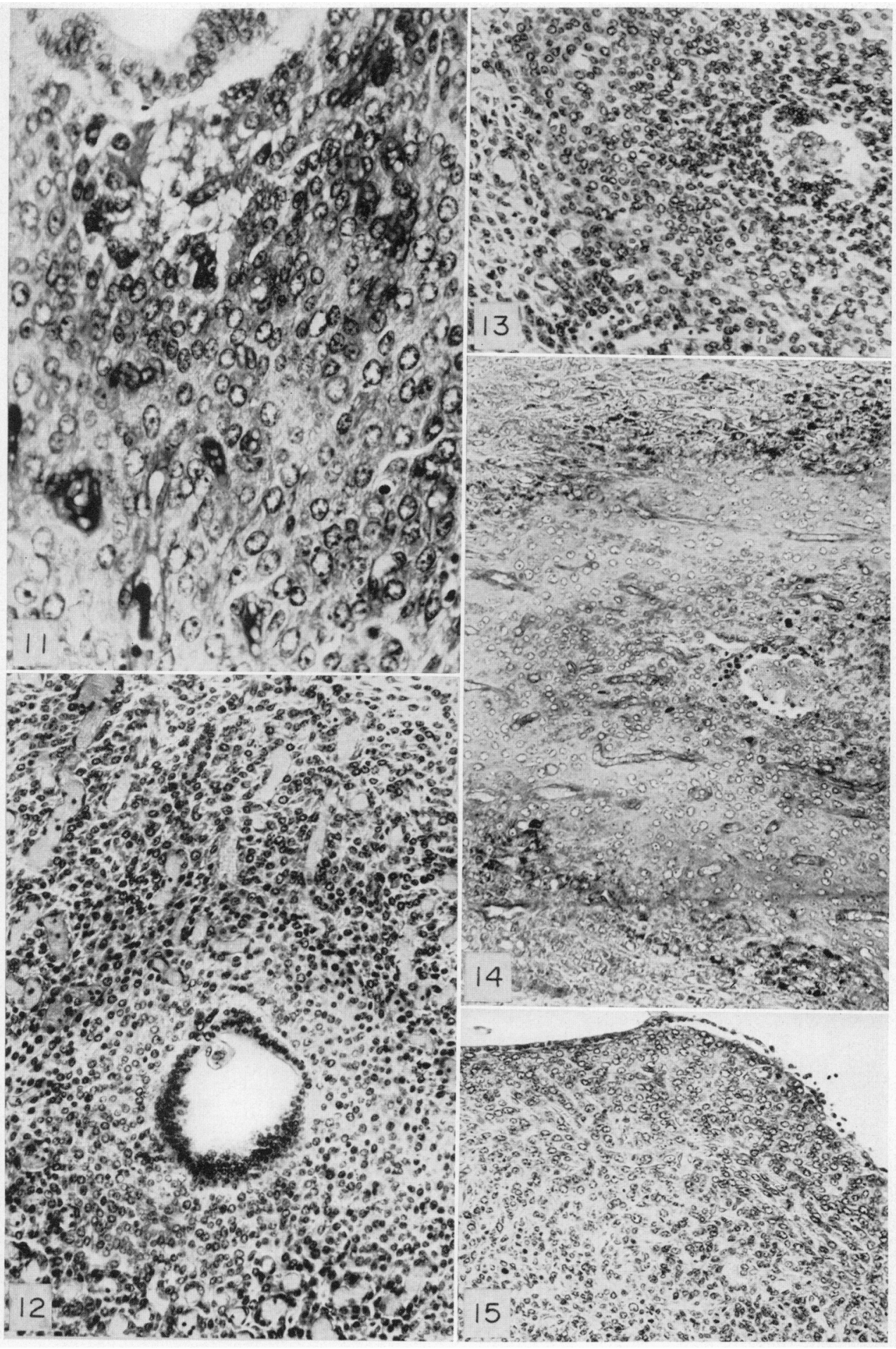


is implanted anti-mesometrially adjacent to the epithelium of the lumen and the blastocyst cavity is surrounded by the well-defined maternal symplasma which, in general, is without the alkaline phosphatase reaction which is very marked in the decidua especially in the mesometrial region. The two types of tissue are equally distinguishable in haematoxylin-stained sections from Bouinfixed material. The diameters of the symplasma nuclei are about half those of the decidual cells which have eosinophilic cytoplasm. The decidual area extends through more than $1 \mathrm{~mm}$ in sagittal sections.

At 8 days, the embryo is characteristically tube-shaped; it projects into an irregular space, the decidual cavity, which includes the blastocyst cavity (Sansom \& Hill, 1931). The decidual area has further enlarged (PI. 1, Fig. 4) and the alkaline phosphatase reaction is again heaviest on the mesometrial side.

\section{Timing and development of the traumatic deciduoma}

Earlier work had shown that threads placed in a sterile uterine horn 3 or 4 days after mating caused little or no decidualization of the stroma up to Day 7 (Deanesly, 1967). Additional uteri were examined in the present series with special reference to the early development and spread of deciduomata in uteri traumatized 5 and 6 days after mating, near the time of ovo-implantation. Deciduomata were classified as undeveloped, developing or large and differentiated. If the stromal tissues in the region of the thread showed only an apparent increase in the subepithelial cells, such as can be seen in control luteal phase uteri, the deciduoma was considered undeveloped. Such a condition was found in five out of eight traumatized uteri in females killed on Day 6. In the region of the traumatizing thread, alkaline phosphatase might appear before the deciduoma was distinguishable in routine histological sections. Early developing deciduomata could be found 2 days after traumatization on Day 4 but only a small area round the thread was affected.

Decidual tissue developed more rapidly when threads were placed on Day 5 or 6. In an animal killed $24 \mathrm{hr}$ after traumatization on Day 5, the decidual tissue had spread through more than $1 \mathrm{~mm}$ and active cell division could be seen in the surrounding stroma (PI. 3, Fig. 15). In spite of the reactivity of the uterine endometrium, the traumatic deciduoma by no means resembled the implantation decidua appearing in the same sagittal sections (Pl. 3, Fig. 14); the latter showed greater organization and differentiation and the presence of glycogencontaining cells at the circumference.

Of the twelve uteri traumatized on Days 2 to 6 and examined on Day 7, only five contained developing deciduomata, most conspicuous in those traumatized on Days 5 or 6 . These showed active vascularization, a spreading alkaline phosphatase reaction and an increase in the numbers of enlarged stromal nuclei. One day after traumatization on Day 6, the early deciduoma was similar to the one in Pl. 3, Fig. 15, but smaller. In females traumatized on Day 5, deciduomata 2 days later consisted of vascular areas, with active cell division, extending through more than $2.5 \mathrm{~mm}$. Alkaline phosphatase was not examined in these uteri but it was present in younger and older deciduomata and in that of a female traumatized on Day 3. The most advanced of these differs from the organized decidua of the 7-day embryo (Pl. 1, Fig. 3). 
By 8 days after mating, the traumatic deciduomata in five of the nine females were large and irregular, showing much alkaline phosphatase. Active growth had taken place and they were about the same size in section as the corresponding implantation deciduas; mitotic figures could be seen. The nature of the developed deciduoma depended on the actual trauma involved. Cells and nuclei varied in size and appearance but there was nothing corresponding to the well-defined alkaline phosphatase-free zone characteristic of the 6- to 7-day pregnancy deciduas nor was there a tendency for alkaline phosphatase areas to be on the antimesometrial side of the uterine lumen, rather the reverse.

\section{DISCUSSION}

Although there are similar features in the early stages of decidua formation at ovo-implantation and the early stages of a thread-induced deciduoma, the two are readily distinguished in the guinea-pig by the more rapid organization and differentiation of the former. The gradual passage of the blastocyst through the uterine epithelium just after it has shed the zona pellucida, does not involve degeneration or phagocytosis of the epithelial or stromal cells. In sections, the epithelial cells just before ovo-implantation appear to be reduced in height, perhaps stretched, at the point of entry but the same cells appear normal when the blastocyst is part way through to the subepithelial stroma. At this early stage, an alkaline phosphatase reaction develops in the stroma localized round the embryo but spreading over an extensive area, not confined to the antimesometrial side of the uterus (Pl. 1, Figs. 2 to 4).

Alkaline phosphatase is regarded as an early sign of tissue differentiation (Finn \& Hinchliffe, 1964) and it may appear in the guinea-pig before decidualization is visible in routine sections, as in the mouse (Finn \& McLaren, 1967). Other early indications of decidual reaction in the stroma at implantation are an increase in vascularization and cell division and nuclear enlargement. Thread traumatization will stimulate all these processes in a luteal phase uterus of an unmated guinea-pig from about the 5 th day of the cycle but the spread of the reaction from the actual traumatized area is at first more gradual although the thread stimulus might be considered more extensive than that of the blastocyst.

The organized decidua, developed round the embryo on Days 6 and 7, has a distinctive inner zone with small nuclei, the maternal symplasma; this lacks the intense alkaline phosphatase reaction shown by the outer decidual cells. Further, when the $6 \frac{1}{2}$-day decidua is contrasted with a traumatic deciduoma in the same sagittal sections, glycogen containing cells are conspicuous at the outer edge of the decidua (PI. 3, Fig. 14). In the adjacent deciduoma 1 day after traumatization, there is nuclear enlargement and cell proliferation, but no comparable differentiation of the tissues ( $\mathrm{Pl}$. 3, Fig. 15). Incidentally, the guinea-pig uterus in the luteal phase, unlike that of the rat, does not decidualize after oil injection.

Although the blastocyst causes no visible cell damage as it passes through the epithelium (cf. Blandau, 1961), it undoubtedly plays an active rôle in inducing changes in the stroma cells. Owers (1970) observed that the trophoblast of 
early guinea-pig embryos, unlike that of 5- to 9-day embryos of the rat, showed strong proteolytic activity, visualized by placing the embryos on darkened gelatine membranes and treating with buffers of various hydrogen ion concentrations. These investigations may add to our understanding of decidua formation at ovoimplantation.

\section{ACKNOWLEDGMENTS}

The author gratefully acknowledges a personal grant from the Medical Research Council and the hospitality of the Agricultural Research Council. Mr Gallup is thanked for the microphotographs and Mrs Janet Cook for much zealous histological work.

\section{REFERENCES}

Aldeen, K. M. \& Finn C. A. (1970) The implantation of blastocysts in the Russian steppe lemming (Lagurus lagurus). F. exp. Zool. 173, 63.

Blandau, R. J. (1961) Sex and internal secretions, Vol. II, Chap. 14. Baillière, Tindall \& Cox, London. Gulling, G. F. A. (1963) Handbook of histological techniques, p. 272. Butterworths, London.

DeANESLY, R. (1960) Implantation and early pregnancy in ovariectomized guinea-pigs. F. Reprod. Fert. $1,242$.

Deanesly, R. (1967) The role of the fertilized egg: reactions in the guinea-pig uterus at ovo-implantation and after thread traumatization. F. Reprod. Fert. 14, 243.

Fins, G. A. \& HrNchliffe, J. R. (1964) Reaction of the mouse uterus during implantation and deciduoma formation as demonstrated by changes in the distribution of alkaline phosphatase. 7. Reprod. Fert. 8, 331.

Finn, G. A. \& McLaren, A. (1967) A study of the early stages of implantation in mice. F. Reprod. Fert. 13, 259.

Manning, J. P., Meli, A. \& Steinetz, B. G. (1966) Alkaline phosphatase and $\beta$-glucuronidase activity in the rat uterus during pregnancy. $\mathbf{F}$. Endocr. $35,385$.

OWERs, N. O. (1970) Comparison of the proteolytic activity of the implanting rat and guinea-pig blastocyst. (Abstract). Anat. Rec. 166, 358.

SANsom, G. S. \& Hirl, J. P. (1931) Observations on the structure and mode of implantation of the blastocyst of Cavia. Trans. zool. Soc. Lond. 21, 295. 